University of Louisville

ThinkIR: The University of Louisville's Institutional Repository

$1-1953$

\title{
An investigation of the effects of wave propagations in an infinite membrane upon the motions of salt particles on the surface
}

Robert Talmadge Maupin

University of Louisville

Follow this and additional works at: https://ir.library.louisville.edu/etd

Part of the Physics Commons

\section{Recommended Citation}

Maupin, Robert Talmadge, "An investigation of the effects of wave propagations in an infinite membrane upon the motions of salt particles on the surface" (1953). Electronic Theses and Dissertations. Paper 3435.

https://doi.org/10.18297/etd/3435

This Master's Thesis is brought to you for free and open access by ThinkIR: The University of Louisville's Institutional Repository. It has been accepted for inclusion in Electronic Theses and Dissertations by an authorized administrator of ThinkIR: The University of Louisville's Institutional Repository. This title appears here courtesy of the author, who has retained all other copyrights. For more information, please contact thinkir@louisville.edu. 


\section{UNIVERS ITY OF LOUISVIILE}

AN INVESTIGATION OF THE EFFECTS OF WAVE PROPAGATONS IN N INFINTTE MEMBRANE UPON THE MOTIONS OF SALT PARTICLW

ON THE SUREACE

A Dissertation

Submitted to the Faculty

of the Graduate School of the UnIversity of Louisvilie

In Partial Fudfildment of the

Requirements for the Degree

of Master of Science

Departane of $P$ hysics

$\mathrm{By}$

Robert Ta Lmadge Maupin

$\frac{1504}{1953}$ 
NAME OF STUDENT: Robert Talma dge Maupin

TITLE OF THESIS: An Investigation of the Effects of Wave Propagations in an Infinite Membrane

upon the Motions of Salt Particles on

the Surface

APPR OVED BY READING COMMITTEE COMPOSE OF THE FOLLOWING MENBERS

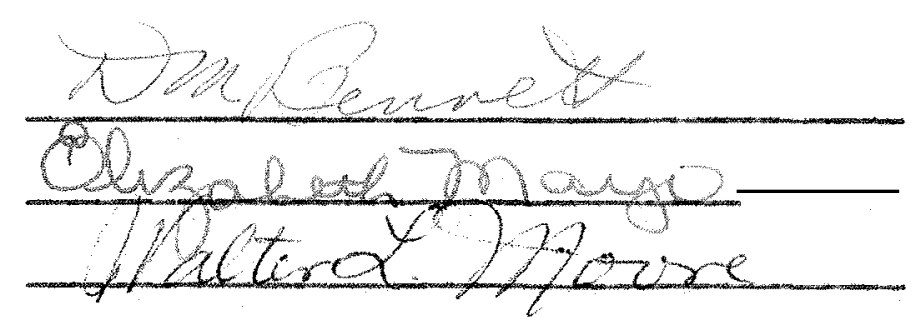

NAME OF DIRECTOR:

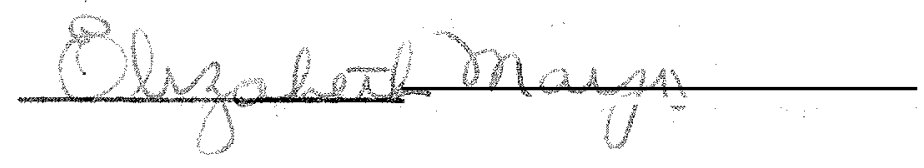

DATE: 


\section{PREFACE}

The subject of this study in vibrational motion is derived from a broader problem originally concolved by Mr. Henry Esterly of the depatment of physios of the University of Louls vilie. His indtial attention to this problem wa aroused in conjunction with certain intensive investigations of elastic properties of, and vibrations in solld media. To him, therefore, is due sincere acknowledgment for his unreserved and continued guidance in inltiating this project.

For Invaluable a id in the analysis of mathematical procedure and the discussion of conclusions immense credtt belongs to my director, Mrs. E. E. Mayo. Additional recognition should be granted Messrs. J. T. Hoffman, Wauer, C. Bryan, and ${ }^{\prime}$. F. Rabb, for tochnical assistance. I should like to express deepest appreciation for the willing counsel and criticism offered by the entire physics staff of the University of Lou1sv1110. 


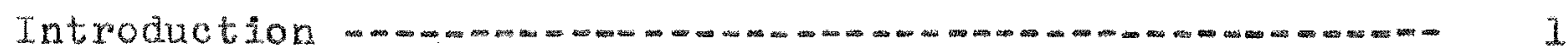

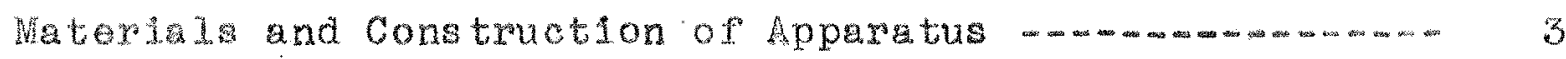

Preliminary Experimental Observations $-m-\infty-m-\infty-m-\infty-6$

Methods or Approach to Problem m-n-m n-m 8

Experimental Determinations and Measurements -............ 16

Correlation of Experimental Results and Theoretical

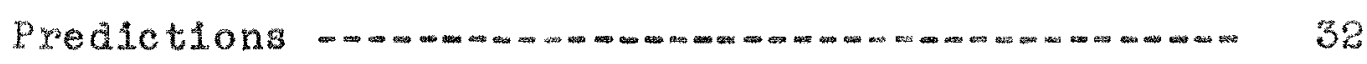

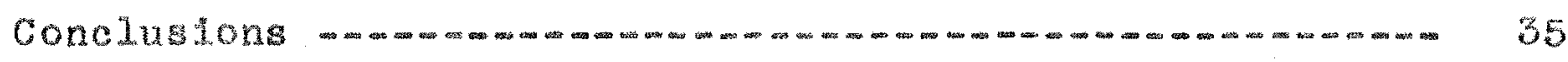

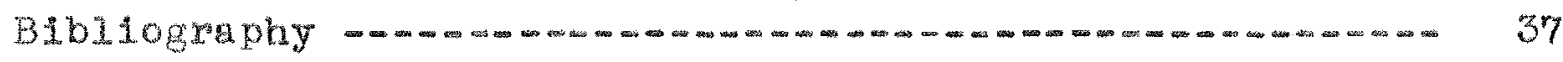


TNTRODUC TION 


\section{TNTRODUCTION}

The large body of motrial already in print which describes the experimental observations of vibrations in membranes does not warant the addition of mere descriptions to the classical theory of vibrations. One is, in fact, led immediately to assume agreement with the conclusion that the experimenta d dsagreements with theory are due simply to overidealizations of the equations of motion. Some such overidealized notions are: The definition of the membrane as an infinltely thin nondisstpative homogeneous lamina; the assumption that the restoring force is due to a uniform and constant tension; and the disrogard of the longitudinal component of tension (and hence of longitudinal displacement and velocity) as negligible.

Most experiments with vibrating membranes have been to achieve approximations of the above conditions for the purpose of securing measuable wave elements in terms of stationary waves established by reflection from the boundary. Yet none of the published reporta seem to indlcate anyone's having made the interesting "mitake" of produc sng an apparent standing wave pattern without reflection from the boundary. Whus, instead of striving for improved replection to satis ry theoretical.

1. See Rayle1gh, J.W.S., The Theory of Sound, (London,1926) I. P. 306 
predictions, we have in our research establjabed a phono mena Im11ar In appearace to the stationary wave where absence of the reflected tranverge wave is assured.

This abserce of a replected wave is observable to the naked eye and by microscoplc inspection of the motions of the salt particles on the membrane. This effect is recorded on the photographic plates in the text exhibiting cases of apparent stationa wave pattern response limited to a centraI xegion of the menbrame. In thls offect is embodicd the "Infinite membrane" concept Incorporated In the titid. It Is hoped that the augested methods of approach to this problem might yield endightment for the Invostagation of other siminar vibrating systems.

1. According to Raylelgh, "Vibrations are called stationary when the motion of each particle of the system is proportlonel to some function of time the same for a 11 particles. "The most general kind of stationary vibration may be regarded as due to the superposition of equal progressive vibretions whose directions of propagation aro opposed. Conversedy, two stationary vibrations may combine into progressive one. See Ibid., p.349 
MATERIALS AND CONSIRUCTION OF APPARATUS 


\section{MATRRTATS AND CONGTUOTYON OF APPARATUS}

The membrane systern was construeted on $3^{3} \times 4^{\prime}$ (inside measurenent) frane with nyan as the vibrating nedurm the frane wes of $2^{n} \times 4^{\prime \prime}$ oak wood, panelled around the top edge with alanted whte pine over whoh the ny on mentrane was stretched. The menwane was first stapled near the outside of the alsnt upper edge of the frame, and tension wo then increased by tacking a rood strip alons the inside edge of the slanted top of the frame. In stretwhing the membane we apolied tension menualy with approxinately radial Brmetry. This differs from the usual method of gratetehing the menbrane on a rectangular fryme where the tena"on is convertionally applied on only two orthogonal dixections. Whe nylon material itself revealed a alghty greater tensile strength in one direction, but otherwide satisfied the desired conditions of uniformity in weave and flexibility. This disparth did not affect the recorded values since a11 readings were taken along the same radial lina. The average thread count was about 120 threads per Inch (unstretehed).

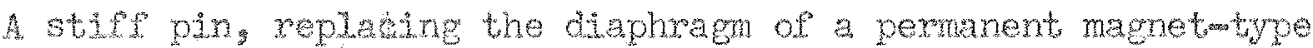
Loudspeaker, aforded the strukotdal driving fores.

The variable mulow recueney oscillator was an $R_{*} \mathrm{C}$.

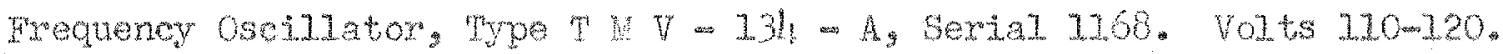
Wetts 15. Gyeles 50 mo

The above variable ose11.bator was cabrated at each test 
frequency against a fixed froqueney $1000 \sim$ Audio. Oscillator Iype 213, Serial No. 674. General Radio Co. U. of L. Laboratory No. E-1206. This standard frequency tuning fork was employed in the comparison method of calibration requiring the intexpetation of lissajous curves. A Type 168 Oscj.lograph, Allen B. Dumont Labs, Inc., Serial No. 552 served as a reliable frequency comparison ind Icator.

A Knjght Phonograph Amplifiew was incorporated for the purpose of controlling the amplitude of the ariving force to ensure no reflection of the impressed wave motion.

Common table salt proved to be the most effective powdex for indicating the nodal patterns of the observed wave phenomena. Sand, powdered rock smalt, and sawdust were tried with less satsfactory results and discarded due to undesirable factors of particle siz, welght and hardness.

Aleroscope (Gaextner $38 \mathrm{~N} / \mathrm{N}$ E F L) was employed in viewing the motion of the alt particles on the membranes and In making thread counts.

The elastic properties of the nylon were investigated by means of a modffled Young's Nodulus apparatus. Atrip of nylon was suspended in the place of the test wire of the Young's Modulus experiment. By a sultable system of hanglng welghts and recording the extenaion of the strip the ratio of tension to elongetion was computed. The area densty was deter. mined by means of the laboratory analytical balance. 
Other materials lncludad a a follow:

1. An static (Roche1Le Salt Crysta1)

Phonograph Cartridge fox detecting

phase changes In longitudina.1 and

transverse diroctions. (The cartw

xidge was orientetad for discriminate

detection of the longltudinal wavo

mot1on. The needle was then bent

through $90^{\circ}$ and the caxtridge was

properiy rotated to detect motion in

the trans verse direction ondy.)

2. an aditional amplifier, suitably

deslgned to amplify the wave signals

transmitted from the crystal cartridge

placed on the membrane surface. 
PRELIM INARY EXPER IMENTAL OBSERVATYONS 


\section{PRELIMINARY EXPER IMENTAL OBSER VATIONS}

The following observations pertain to the preliminaxy performance of the designod apparatus as previously described.

The wave length of the observed wave motion is continuously inversely proportional to the frequency (see photographic plates).

The salt pattern symmetry is not a function of the boundary configuration. (Thls independence of nodal symmetry upon the boundary was aided by the manner of stretehing, namely, with the end in view of attaining radial symmetry.) This method of applying tension is in contrast to that conventLonally employed for rectangular frames, that is, in only two perpendicular directions parallel with the boundary faces.

Somewhat allied to the above observation is the notice. able dependence of the pattern distinctiveness upon the position in which the Ioudspeaker is orientated. The loudspeaker pin (the sinusoidal driving force) definitely had a greater lateral motion in one direction. This characteristic Is to be expected from the definite though sljght lever 1 ike action of the pin support.

The application of an effectivo boundary, namely, by manual exertion, does not affect the pattern if applied outside the observable wave pattern. This observation was not made for a similar application of exertion within the 
pattern.

Even at nodal positions, for the observed wave pattern a transverse component of particle (salt) motion is observed.

The salt particle distribution did not detectably alter the nodal pattern symmetry or the distances between the salt collections, but tended only to affect the radius of the axea of response of the membrane to the driving force.

Repeated microscoplc thread counts revealed very little variation of the elastic properties of the nylon with respect to humidity or temperature conditions. There is no doubt, however, that the prolonged stretching and changing of the tension by the impressed force affected the pattern reproducibility to some degree.

It might be stated, superficlally, that the observed wave patterns conformed in grosser detalis to concentric elipses, and in some cases very closely approximated circles, which would be predicted for the classical transverse vibrations of a nearly circular membrane. At lower frequencles and greater drive the membrane did exhibit familiar patterns due to reflection from the boundary. 
METHOD OF APPROACH TO THE PROBLEM 
The first positive achievement of this project was the establishment of an apparent standing wavel propagation In an infinite medium. The maximum we amplitude is easily controlled by means of a sultable amplifier. Damping reduces this amplitude satisfactorily with a decay in amplitude as a function of distane from the impressed driving source. This damping is well indicated by the observed motions of the salt particles. That the observed pattern is definitely not due to reclection is attested to by the continuously inverse relationship between pattern formation and frequency. It is common knowledge that for our effect to be due to reflection the distance from the source to the boundary would have to be equal to an Integral multiple of one-half the wave length. If it is granted that wo do have an apparent stand Ing wave propagation in an infinite medium, wo soek next a valid explanation of our observed phenomena.

The exhibition of the Independence of the pattern formation upon particle distribution eliminates the suggestion that any such damping by the particles efects a "virtual boundary" on the membrane.

I. By apparent atanalng wave we refer to a wave effoct which is not visibly altered in space with respect to time. The herein proposed theory of the true nature of the effect will be clarifled later. 
Turning to an inspection of the particle motion on the membrane one grasps the prospetive fruitfulness of describIng the complete motions of afferent portions of the membrane in terms of the energy imparted to the particles at the surface. An attempt would then be advanced to quantize the vibrating system as satiafying the conditions governing the particle motions.

The expressions of the possible motions of the particles In the membrans are derived from a consideration of the stresses, strains and vibrations of a deformable body ${ }^{l}$. The equations of motion of an elastic body are given byz

$$
\begin{gathered}
\rho \frac{\partial^{2} \xi_{i}}{\partial t^{2}}=\sum_{j}\left[(\lambda+\mu) \frac{\partial^{2} \xi_{j}}{\partial x_{i} \partial x_{j}}+\mu \frac{\partial^{2} \xi_{i}}{\partial x_{j}^{2}}\right]=F_{\text {orce }}\left(\frac{1}{\text { volume }}\right) \\
\text { where } d F_{i}=\sum_{j} \frac{\partial T_{i j}}{\partial x_{j}} d x_{1} d x_{2} d x_{3}, \rho=\text { density } \\
\frac{\partial^{2} \xi_{i}}{\partial t^{2}}=\text { acceleration of volume element } d x_{1} d x_{2} d x_{3} \\
i=1,2,3 . \quad \mu=\text { shear modulus of elasticity } \\
\text { given by } T_{i j}=\text { shearing stress }=\mu \tan \theta \\
\theta=\tan ^{-1}\left(\frac{\partial \xi_{i}}{\partial x_{j}}\right)
\end{gathered}
$$

1. For this treatment see Slater and Frank, Mechanics

(Now York, 1947), pp. 206-222. Also see Page, Introduction to Theorotical Physics (New York, 1935), pp. 173-179. 2. SIater and frank, op cit, p. 218. 
$-10=$

$\frac{\partial \xi_{i}}{\partial x_{j}}=$ pure strain (shearing)

$\lambda=$ tension modulus of elasticity, is given by

$$
\begin{aligned}
& K=-\frac{1}{\rho} \frac{\Delta V}{V}=\frac{1}{\lambda+\frac{2}{3} \mu}=\text { compressibility. } \\
& \frac{\Delta V}{V}=\text { dilatation }=\nabla \bar{\xi}=\frac{\partial \xi_{1}}{\partial x_{1}}+\frac{\partial \xi_{2}}{\partial x_{2}}+\frac{\partial \xi_{3}}{\partial x_{3}}
\end{aligned}
$$

This equation of motion for displacement employs

Hooke's law which in tensor notation is expressed as

follows:

$$
\begin{aligned}
T_{i j}=\lambda \sigma_{i j} \sum_{k} \frac{\partial \xi_{k}}{\partial x_{k}}+\mu\left(\frac{\partial \xi_{i}}{\partial x_{j}}+\frac{\partial \xi_{j}}{\partial x_{i}}\right), & \begin{aligned}
\delta_{i j} & =\sum_{n} \alpha_{n i} \alpha_{n j} \text { for orthogonality - } \\
& =1, i=j \quad \text { normalizing conditions } \\
& =0, i \neq j \\
& \alpha_{i j}=\text { direction cosines }
\end{aligned}
\end{aligned}
$$

The diagonal components of the above form of Hooke's law are,

$$
\begin{aligned}
& T=(\lambda+2 \mu) \frac{\partial \xi_{1}}{\partial x_{1}}+\lambda \frac{\partial \xi_{2}}{\partial x_{2}}+\lambda \frac{\partial \xi_{3}}{\partial x_{3}} \\
& O=\lambda \frac{\partial \xi_{1}}{\partial x_{1}}+(\lambda+2 \mu) \frac{\partial \xi_{2}}{\partial x_{2}}+\lambda \frac{\partial \xi_{3}}{\partial x_{3}}
\end{aligned}
$$


$-11-$

$$
O=\lambda \frac{\partial \xi_{1}}{\partial x_{1}}+\lambda \frac{\partial \xi_{2}}{\partial x_{2}}+(\lambda+2 \mu) \frac{\partial \xi_{3}}{\partial x_{3}} \text {, }
$$

or, $T=Y \frac{\partial \xi_{1}}{\partial x_{1}}$ where $Y=(\lambda+2 \mu-2 \lambda \sigma)$.

$$
\sigma=-\frac{\partial \xi_{2} / \partial x_{2}}{\partial \xi_{1} / \partial x_{1}}=\text { Poisson's ratio }
$$

$\approx \frac{1}{3}$ for most materials.

$$
Y=\text { Young's modulus. }
$$

Our stated equations of motion may be simplified by considering a wave in which displacement is a function of distance in one direction only, let us say, of $x$, only. The components of our wave equation then become.

$\rho \frac{\partial^{2} \xi_{1}}{\partial t^{2}}=(\lambda+2 \mu) \frac{\partial^{2} \xi_{1}}{\partial x_{1}^{2}},(\lambda+2 \mu)=Y_{\text {if } \sigma \text { is }}$ neglected.

$=$ longitudinal equation of motion. $\rho \frac{\partial^{2} \xi_{2}}{\partial t^{2}}=\mu \frac{\partial^{2} \xi_{2}}{\partial x_{1}^{2}}=$ transverse equation of motion. $\rho \frac{\partial \xi_{3}}{\partial t^{2}}=\mu \frac{\partial^{2} \xi_{3}}{\partial x_{1}^{2}}=$ transverse equation of motion. 
These equations exhibit two independent types of waves. The longltudinal wave can be propagated with a velocity $C_{1}=\sqrt{\frac{Y}{\rho}}$. The transverse waves are at right angles to the direction of propagation and the velocity is $\mathrm{c}_{t}=\sqrt{\frac{\mu}{\rho}}$.

In our case we recognaze the existuce of two such waves in the membrane, longitudina 1 and transverse. These are expressed in the following forms:

$$
\begin{aligned}
& \eta=A \cos \left\{\omega t-k_{1} x\right\} e^{-\alpha x}=\text { transverse displacement, } k_{1}=\frac{2 \pi}{\lambda_{T}} . \\
& \xi=B \cos \left\{\omega t-k_{2} x\right\} e^{-\beta x}=\text { longitudinal displacement, } k_{2}=\frac{2 \pi}{\lambda_{L}} .
\end{aligned}
$$

These are the two motions of the membrane and hence those which may be imparted to the salt particles.

At each point in the membrane the transverse velocity will at some time be zero. At each point in the membrane the longitudinal velocity, will at some time be zero. At certain points in the membrane, there should exist a phase relationship between the longitudinal and trans verse waves such that the longitudinal and transverse velocities will be zero simultaneously. And at sufficiently high frequencies the recurrence of such simultaneous zero wave Instantaneous velocities should be of sufficient periodicity to establish "pseudo-stationary" waves. Perhaps a better manner of expressing this phenomena is suggested by the observation that thero may be vertical separation of the salt from the membrane even at the places where it collects. Therefore, the salt forms at the places where it 
Leaves the screen whth zero horizontal velodity. This last consideration is signifieant for consldering the precise nature of the particle-membrane vibrating systom.

Returning to tho expressions for the displacements and velocities of the two waves in the memorane we state,

$$
\begin{aligned}
\dot{\eta} & =-\omega A \sin \left\{\omega t-\frac{2 \pi x}{\lambda_{T}}\right\} e^{-\alpha x}=\text { transverse particle velocity. } \\
& =0 \text { for }\left\{\omega t-\frac{2 \pi x}{\lambda_{T}}\right\}=m \pi, n=\text { integer. } \\
\dot{\xi} & =-\omega B \sin \left\{\omega t-\frac{2 \pi x}{\lambda_{L}}\right\} e^{-\beta x}=\text { longitudinal particle velocity. } \\
& =0 \text { for }\left\{\omega t-\frac{2 \pi x}{\lambda_{L}}\right\}=m \pi, m=\text { integer. }
\end{aligned}
$$

To determine the spatial quantization for the condtions of observed perticle motion, therefore, we eliminate wt from the two above terms in the brackets, for consideration of the "space frequency" portion of the functions, name $1 y, \frac{2 \pi x}{\lambda_{T}}$ and $\frac{2 \pi x}{\lambda_{L}}$.

$$
\begin{gathered}
\text { We obtain, wt }=n \pi+\frac{2 \pi x}{\lambda_{T}}=m \pi+\frac{2 \pi x}{\lambda_{L}} \\
2 x\left(\frac{1}{\lambda_{T}}-\frac{1}{\lambda_{L}}\right)=m-n, \text { or, } x=\frac{m-n}{2}\left(\frac{\lambda_{L} \lambda_{T}}{\lambda_{L}-\lambda_{T}}\right)
\end{gathered}
$$

1. The terms $e^{-\alpha x}, e^{-\beta x}$ are introduced to satisfy the damped nature of the waves, and re the respective damping factors to be experimenta $11 y$ determined. 
$-14=$

In terms of frequency, $x=\frac{P}{2}\left(\frac{C_{L} C_{T}}{C_{L}-C_{T}}\right) \cdot$ frequency $^{-1}$ defines positions where the salt collects.

$$
p=(m-n)=\text { integer }
$$

$C_{L}=$ velocity of longitudinal wave propagation.

$C_{T}=$ velocity of transverse wave propagation.

It would then be left to determine the values of $c_{1}$ and $C_{t}$ to check the validity of our spatial quantization of the particlo-membrane system.

Another attempt to explain the particle distributions considered the kinetic energy of the membrane waves, which should be given by -

$$
\begin{aligned}
& \text { K.E. }=\frac{m}{2}\left(\dot{\eta}^{2}+\dot{\xi}^{2}\right)=\frac{1}{2} m \omega^{2} A^{2} \sin ^{2}\left(\omega t-k_{1} x\right)+\frac{1}{2} m \omega^{2} B^{2} \sin ^{2}\left(\omega t-k_{2} x\right) \text {. } \\
& \frac{\partial\left(K_{1} E_{1}\right)}{\partial x}=-m \omega^{2} A^{2} k_{1} \sin \left(\omega t-k_{1} x\right) \cos \left(\omega t-k_{1} x\right) \\
& -m \omega^{2} B^{2} k_{2} \sin \left(\omega t-k_{2} x\right) \cos \left(\omega t-k_{2} x\right)=0
\end{aligned}
$$

for minimum value if $\frac{\partial^{2}(K . E .)}{\partial x^{2}}>0$.

$$
\begin{gathered}
\frac{\partial\left(K_{1} E_{1}\right)}{\partial x}=-\frac{m \omega^{2} A^{2}}{2} \sin 2\left(\omega t-K_{1} x\right)-\frac{m \omega^{2} B^{2}}{2} \sin 2\left(\omega t-k_{2} x\right) \\
=O=R \sin 2\left(\omega t-K_{1} x\right)+\sin 2\left(\omega t-k_{2} x\right) . \\
R=\frac{A^{2} K_{1}}{B^{2} K_{2}}
\end{gathered}
$$

The conditions satisfying the above minima are,

$2 \omega t-2 k_{1} x=0 \pm 2 n \pi$, and $2 \omega t-2 k_{2} x=0 \pm 2 m \pi$,

or, $\omega t=k_{1} x \pm n \pi=k_{2} x \pm m \pi . \quad x=\frac{m-n}{2}\left(\frac{\lambda_{L} \lambda_{T}}{\lambda_{L}-\lambda_{T}}\right)$.

This result agrees with that of our first consideration. Expanding equation (3.3), we obtain 


$$
\begin{aligned}
& \frac{\partial\left(K_{1} E_{.}\right)}{\partial x}=R \sin 2 \omega t \cos 2 K_{1} x-R \cos 2 \omega t \sin 2 K_{1} x \\
&+\sin 2 \omega t \cos 2 k_{2} x-\cos 2 \omega t \sin 2 k_{2} x=0 .
\end{aligned}
$$

Collecting coepricients of $\sin 2 \omega t$ and cos $2 \omega t$, obtain $\sin 2 \omega t\left(R \cos 2 k_{1} x+\cos 2 k_{2} x\right)-\cos 2 \omega t\left(R \sin 2 k_{1} x+\sin 2 k_{2} x\right)=0$

$$
\text { if } \begin{aligned}
R \cos 2 k_{1} x+\cos 2 k_{2} x & =\cos 2 \omega t, \\
R \sin 2 k_{1} x+\sin 2 k_{2} x & =\sin 2 \omega t .
\end{aligned}
$$

Squaring and adding we get $\cos 2 x\left(K_{1}-K_{2}\right)=-\frac{R}{2}$.

$$
x=\frac{\Phi \pm 2 n \pi}{4 \pi}\left(\frac{\lambda_{L} \lambda_{T}}{\lambda_{L}-\lambda_{T}}\right) \cdot \Phi=\cos ^{-1}\left(-\frac{R}{2}\right) \text {. }
$$

Other conditions satisfying equation (4.2) are,

$$
\begin{aligned}
& R \cos 2 k_{1} x+\cos 2 k_{2} x=0 . \\
& R \sin 2 k_{1} x+\sin 2 k_{2} x=0
\end{aligned}
$$

Dividing these equations, we get

$$
\begin{aligned}
& \cot 2 k_{1} x=\cot 2 k_{2} x, \text { or, } \\
& 2 k_{1} x+n \pi=2 k_{2} x+m \pi . \\
& x=\frac{(m-n) \pi}{2\left(k_{1}-k_{2}\right)}=\frac{p}{4}\left(\frac{\lambda_{L} \lambda_{T}}{\lambda_{L}-\lambda_{T}}\right) .
\end{aligned}
$$

This result predicts exactly twice as many positions for particle ring formations as predicted by the velocity considerations. This result also includes the same points predicted earlier. 
EXPERTMENTAL DETERMINATIONS AND MEASUREMENTS 
To Deterwathe the Velocity of Longitudinal Wave Propagation in the Mernbrane in Terms of the Elastic Properties of the Material

The velocity of propagation of the longitudinal wave is given as $C_{1}=\sqrt{\frac{Y}{p}}, Y=$ Young's Modulus $=\left(\frac{\text { dynes }}{\mathrm{cm}^{2}}\right) \cdot \rho=$ donsity $=\left(\frac{\mathrm{gm}}{\mathrm{cm}^{3}}\right)$ Young's hodulus is dofined by Hooke's law as the ratio of the applied stress to the resulting extenslonal strain, or $Y=\left(\frac{\text { Applied Foree } \times \text { Unstrained length }}{\text { Area }}\right)$, both stress and strain as sumed small enough to prevent permanent deformation. The table below records the extensions of elongations with the corresponding stresses.

Plate No.1.

\begin{tabular}{|c|c|c|c|c|c|c|}
\hline & est & & & Test & 2 & \\
\hline Force & 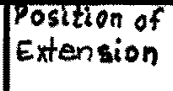 & \begin{tabular}{|l|} 
Position of \\
Extension
\end{tabular} & $\begin{array}{l}\text { Average } \\
\text { Position of }\end{array}$ & $\begin{array}{l}\text { Position of } \\
\text { Extension }\end{array}$ & $\begin{array}{l}\text { Position of } \\
\text { Extension }\end{array}$ & $\begin{array}{l}\text { Average } \\
\text { Position }\end{array}$ \\
\hline $\begin{array}{l}\text { Applied } \\
\text { (gm.) }\end{array}$ & $\begin{array}{l}\text { Adding } \\
\text { w eights } \\
\text { cmm }\end{array}$ & $\begin{array}{l}\text { Removing } \\
\text { Weights } \\
\text { com mit }\end{array}$ & {$\left[\begin{array}{c}\text { Extension } \\
(\mathrm{m} \mathrm{m})\end{array}\right.$} & $\begin{array}{l}\text { Adding } \\
\text { Weights } \\
\text { (m m) }\end{array}$ & $\begin{array}{l}\text { Removing } \\
\text { weights } \\
\text { (mmi) } \\
\end{array}$ & $\begin{array}{l}\text { Extension } \\
(\mathrm{mm})\end{array}$ \\
\hline 1050 & 12.65 & 13.16 & 12.905 & 13.16 & & \\
\hline 1250 & 13.15 & 14.25 & 13.70 & 13.66 & 14.69 & 14.175 \\
\hline 1450 & 14.14 & 15.07 & 14.605 & 14.81 & 15.66 & 15.235 \\
\hline 1650 & 15.04 & 15.77 & 15.405 & 15.51 & 16.06 & 15.815 \\
\hline 1850 & 15.96 & 15.96 & $15 . \% 0$ & 16.75 & 16.75 & 16.750 \\
\hline
\end{tabular}




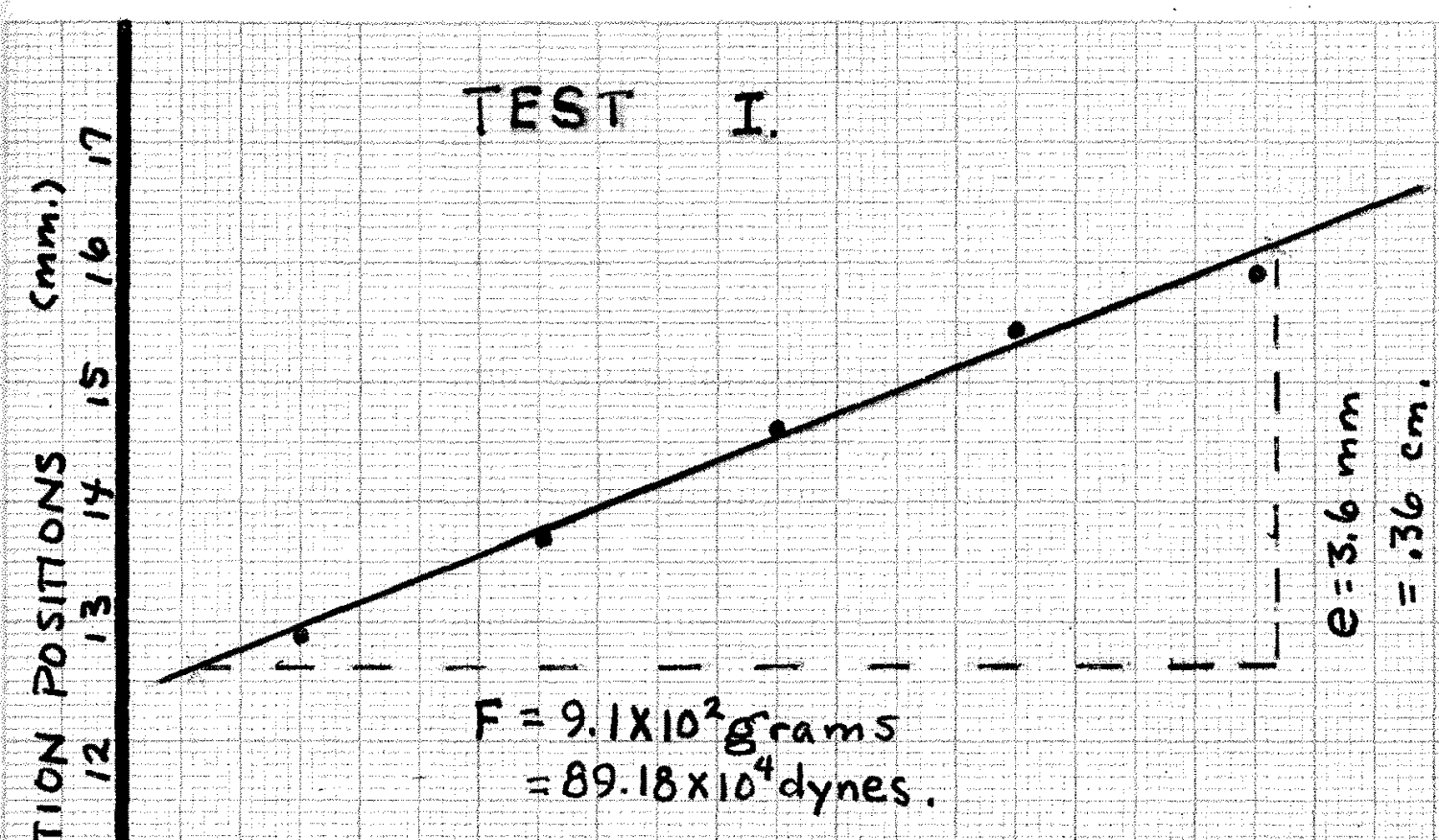

DETERMINATION OF $\frac{F}{e}$ FOR NYLON STRIP

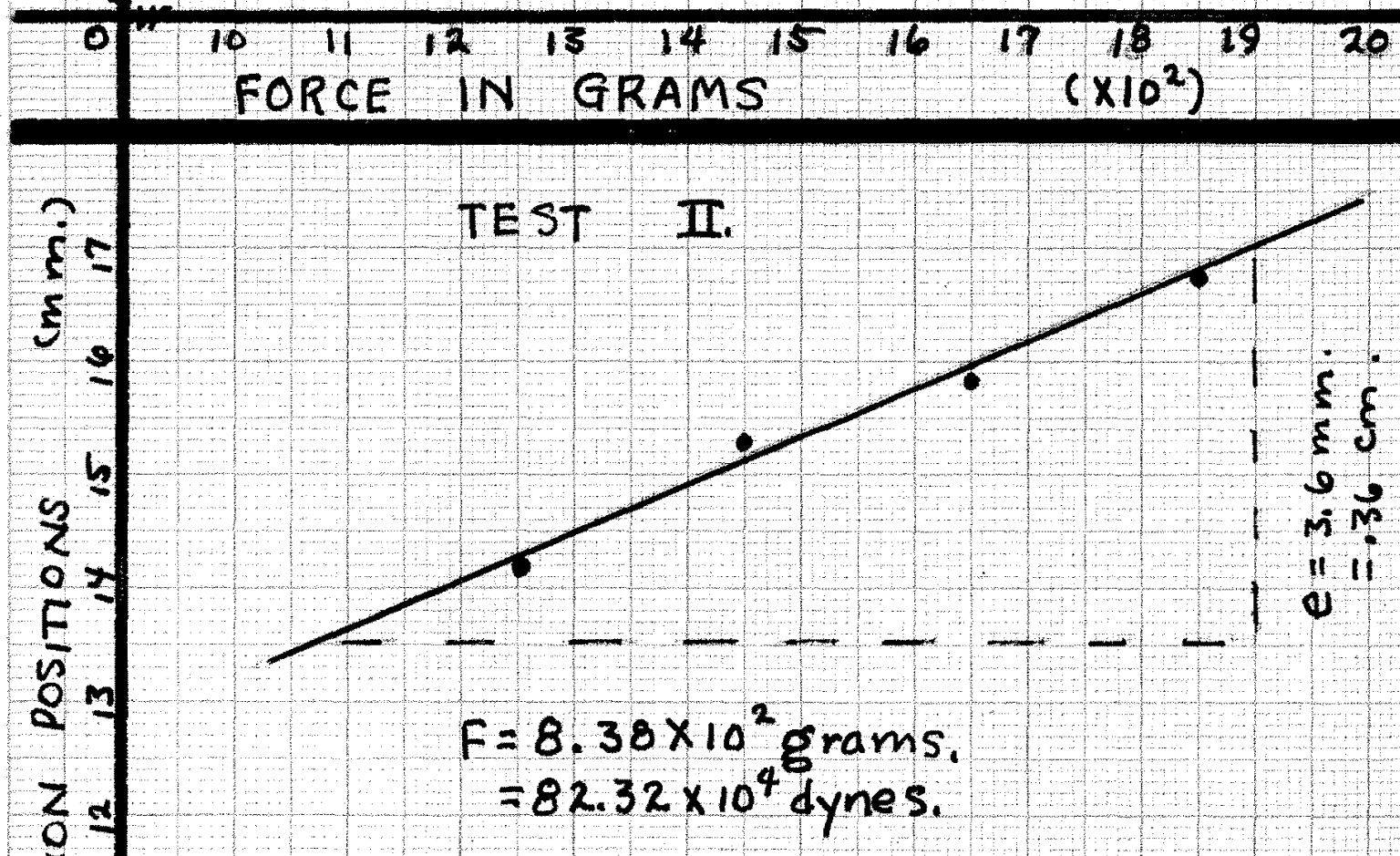

F

$\leftarrow$

$G=$

2

90

DETERMINATION OF $\frac{F}{e}$ FOR NYLON STRIP

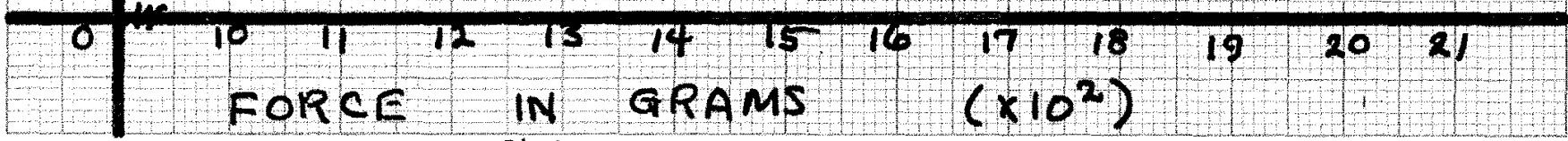
Plate No. 2. 
Thus for two tests we obtain $(\bar{\theta})_{1}=\frac{89.18 \times 10^{4}}{.360}$ dynes $/ \mathrm{cm}=248.5 \times 10^{4} \mathrm{dynes} / \mathrm{cm}$, and $\left(\frac{F}{\mathrm{e}}\right)_{2}=\frac{82.32 \times 10^{4}}{.360}=$ $228.5 \times 10^{4}$ dynes $/ \mathrm{cm} . \quad\left(\frac{\mathrm{F}}{\mathrm{e}}\right)=238.5 \times 10^{4} \mathrm{dynos} / \mathrm{cm}$. There-

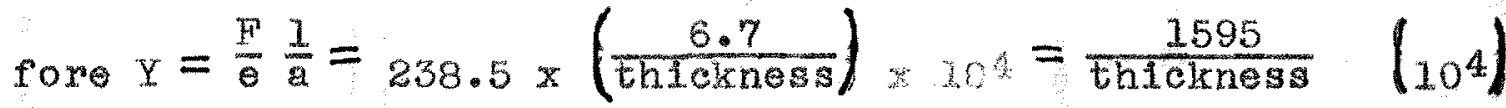
aynes/cme. $c_{1}=\sqrt{\frac{Y}{\rho}}=\sqrt{\frac{1595 / t \times 10^{4}}{36.38 \times 10-4 / t}}=10^{5} \sqrt{\frac{15.95}{36.38}} \mathrm{~cm} / \mathrm{sec}$ $=6.61 \times 10^{4} \mathrm{~cm} / \mathrm{sec}$. 
Plate No. 3

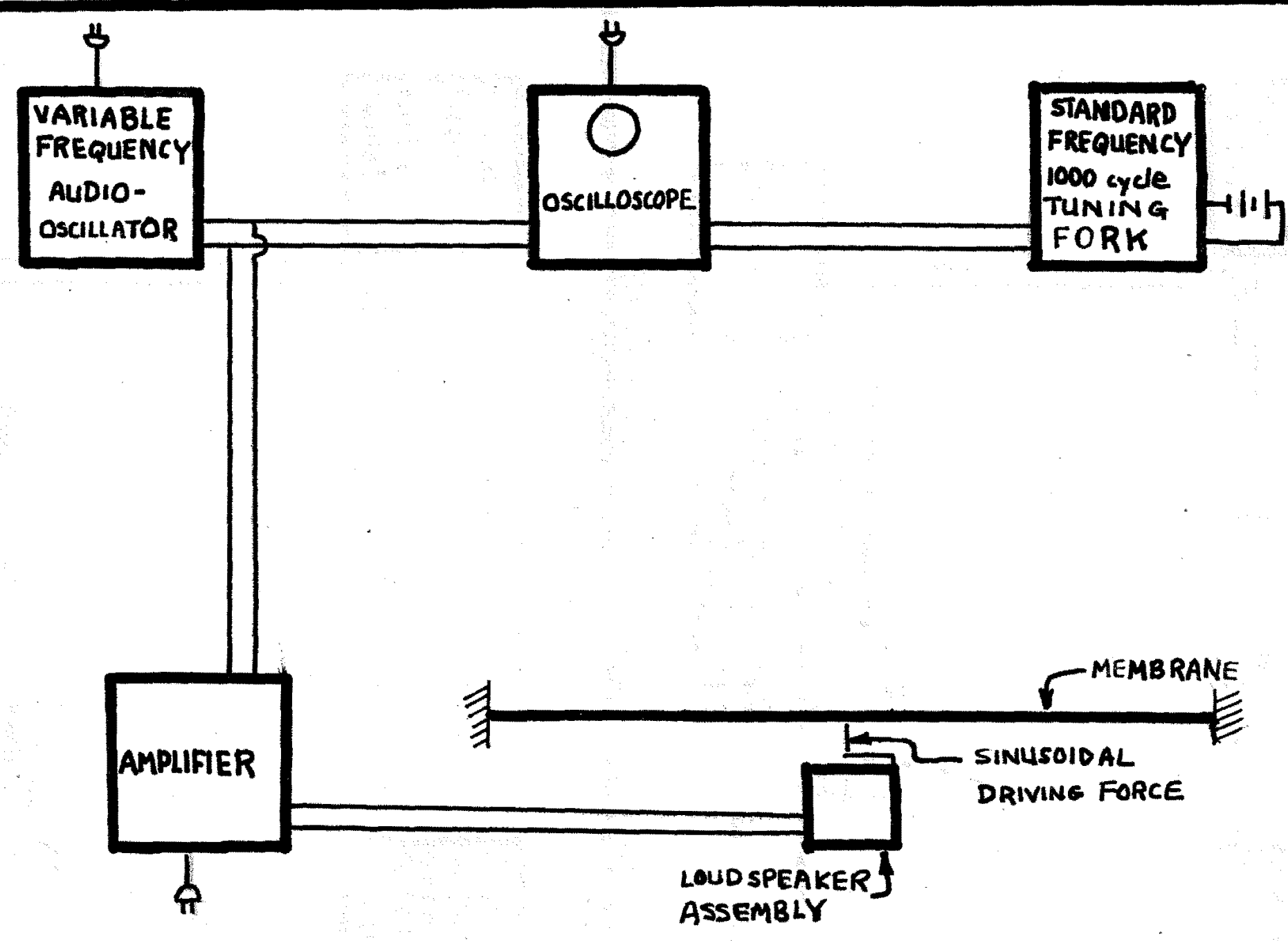

DIAGRAM OF MEMBRANE SYSTEM 

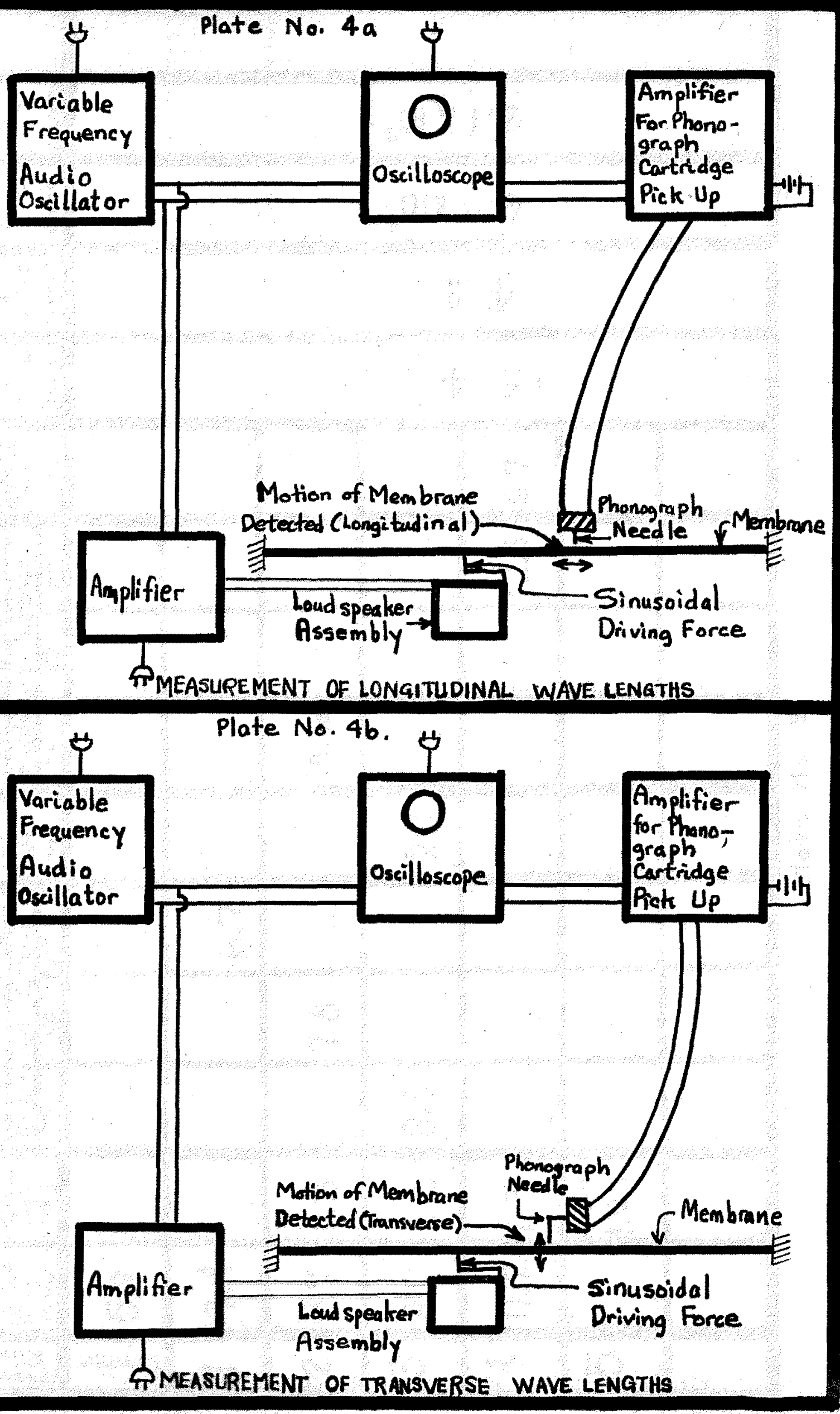
Frequency $=5000$ cycles $/ \mathrm{sec}$.

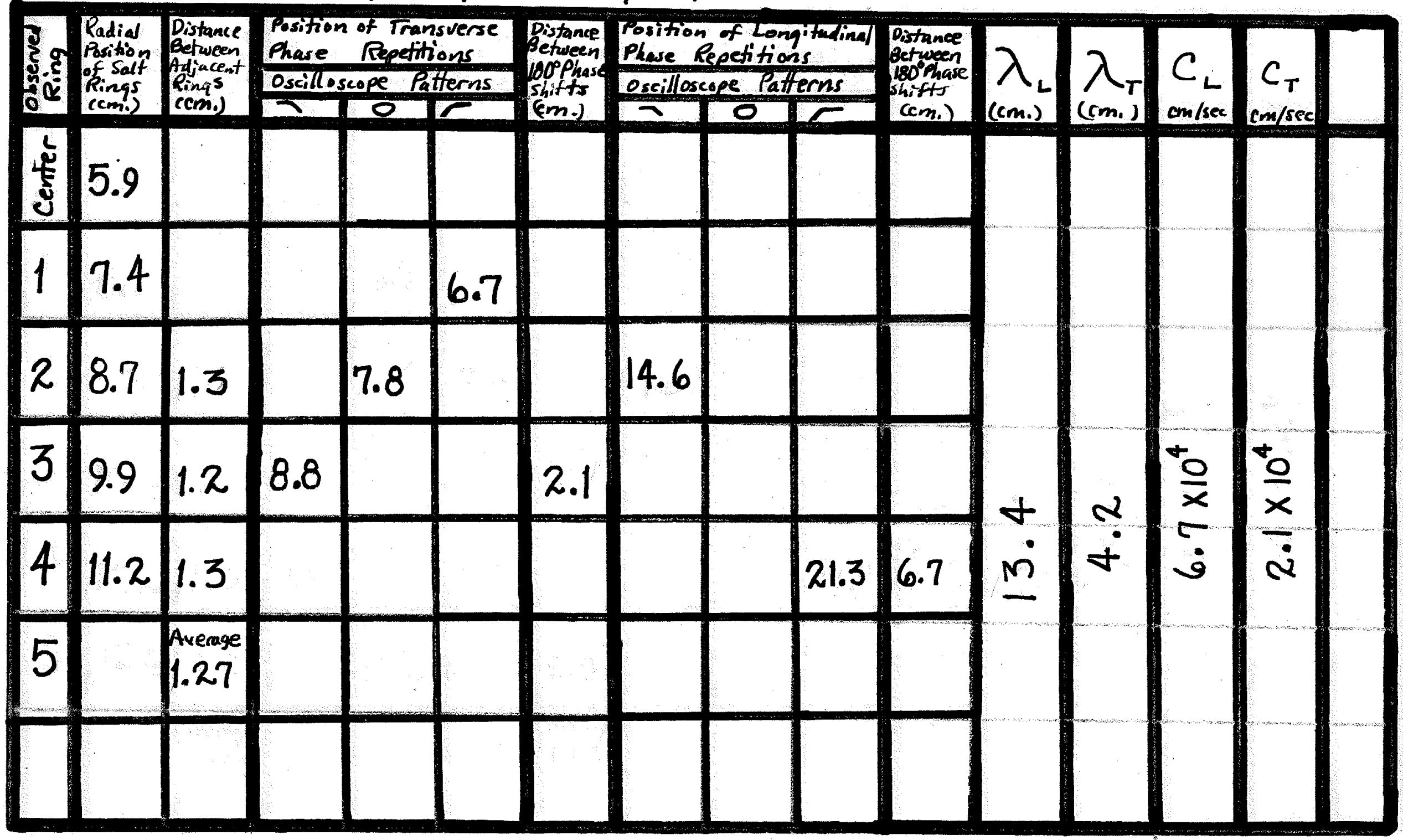

Plate No. 5. 
Frequency $=6000$ eycles $/ \mathrm{sec}$.

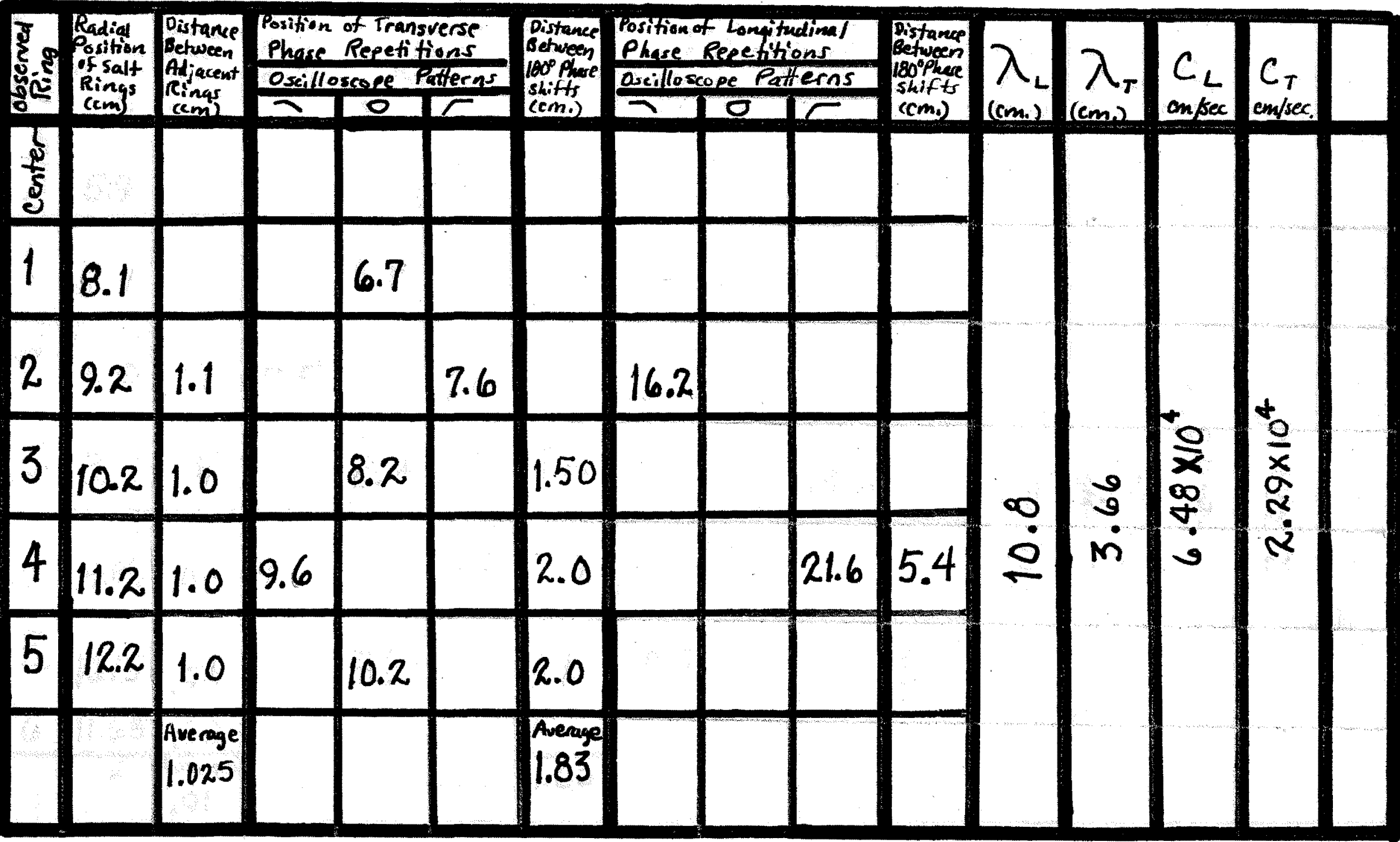

Plate No. 6. 
Frequency $=7000$ eycles $/ \mathrm{sec}$.

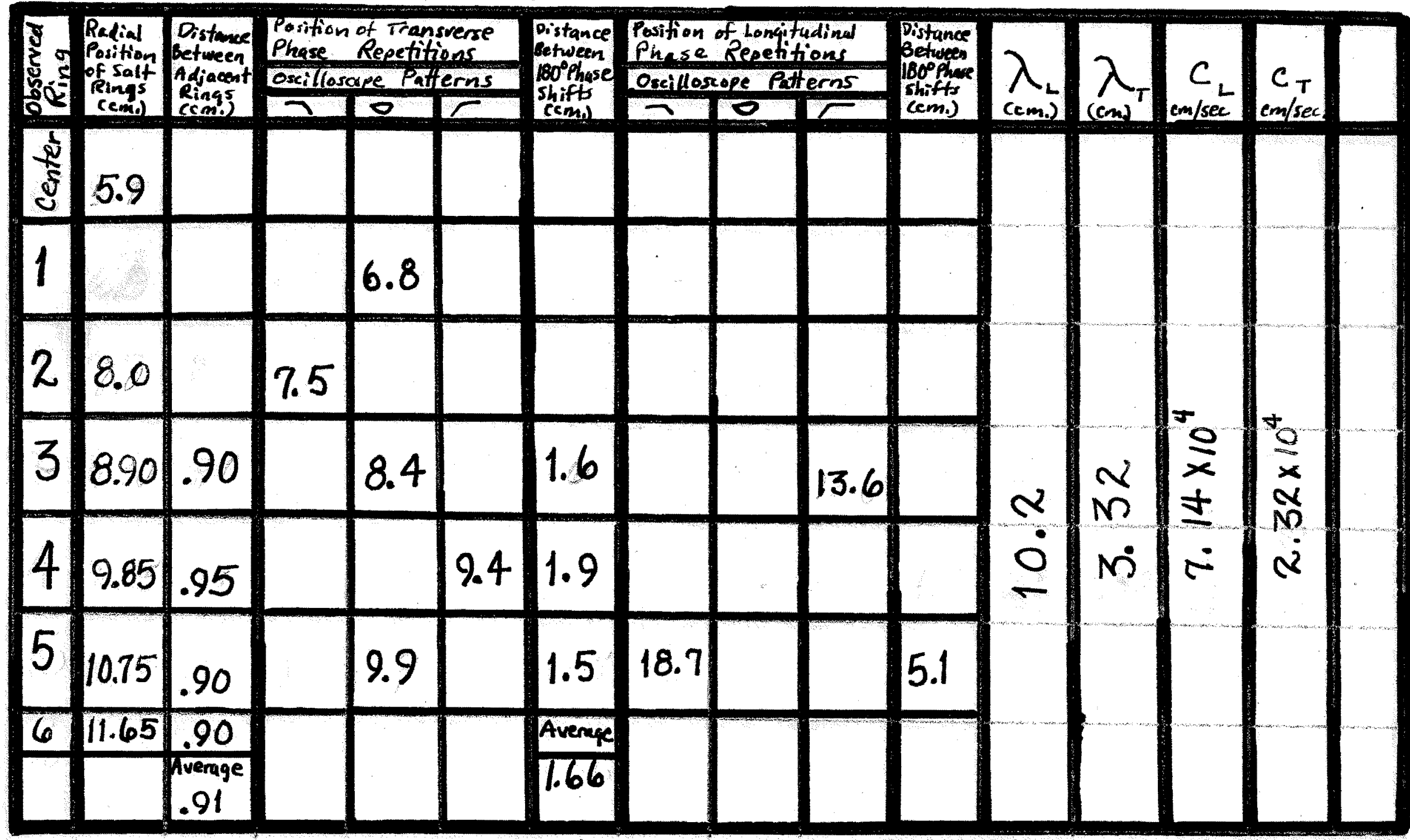

Plate No. 7 
Frequency $=8000$ cycles $/ \mathrm{sec}$.

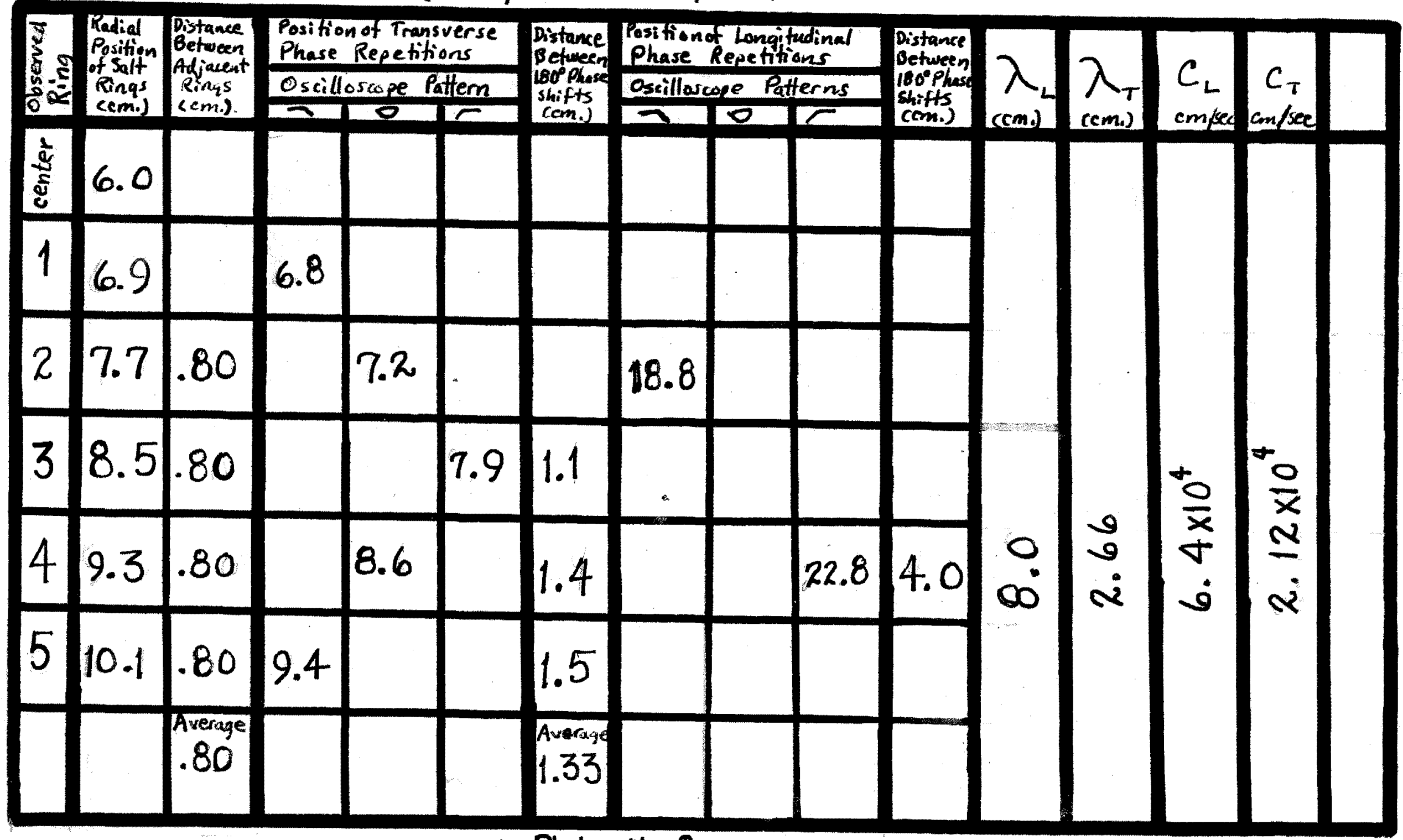

Plate No. 8 . 
Plate No. 9.

Frequency $=2000 \mathrm{cycles} / \mathrm{sec}$. 
Plate No. 10. Frequency $=3000$ cycles $/ \mathrm{sec}$. 
Plate No.11.

Frequency $=4000 \mathrm{cycles} / \mathrm{sec}$. 
Plate No. 12.

Frequency $=5000$ cycles $/ \mathrm{sec}$. 
Plate No. 13.

Frequency $=6000$ cycles/sea. 
Plate No. 14 Frequency $=7000 \mathrm{cycles} / \mathrm{sec}$. 
Plate No .15.

Frequency $=8000 \mathrm{cycles} / \mathrm{sec}$.

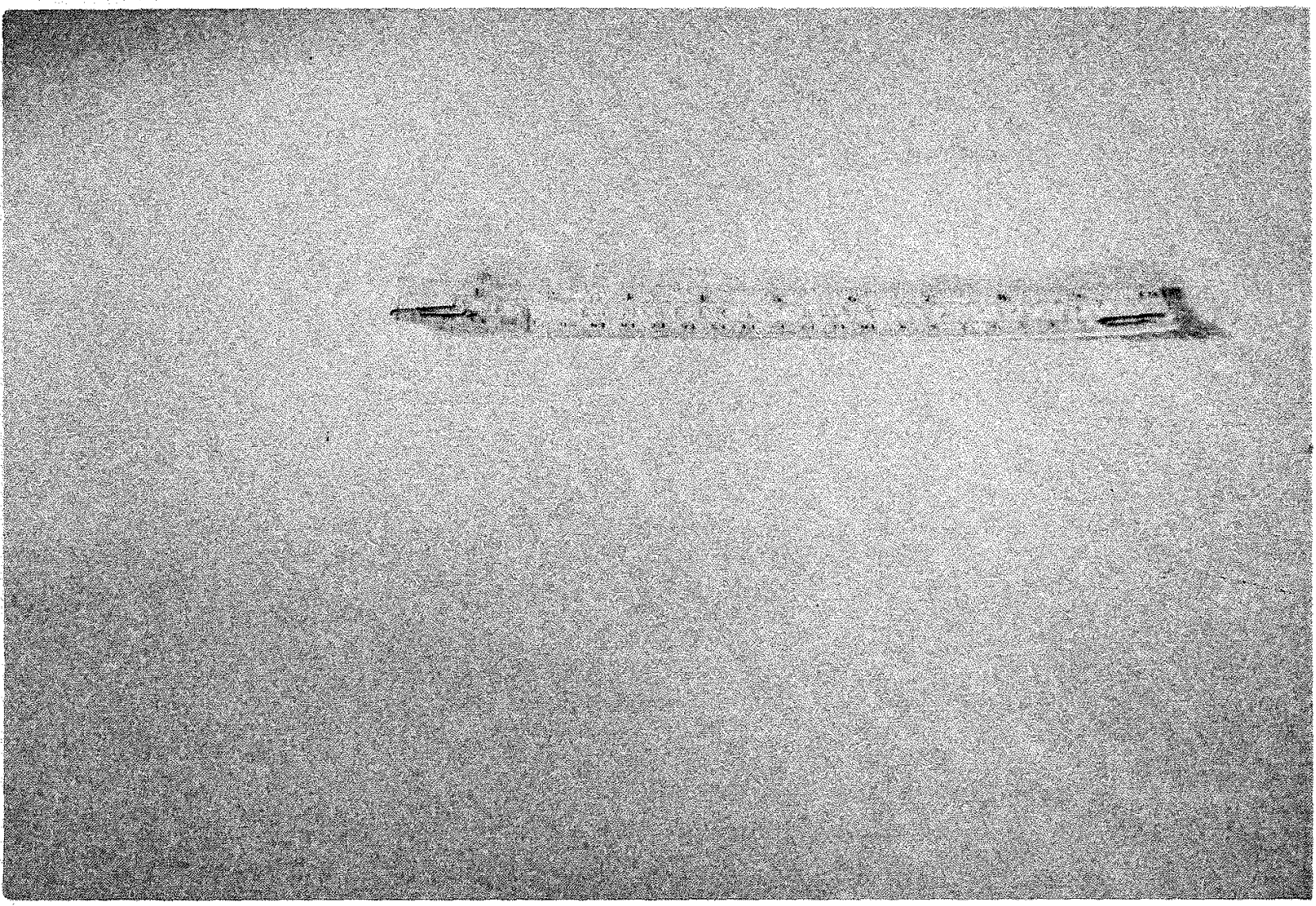

$\underline{w}$ 
CORRELATION OF

EXPER IMENTAL RESULTS

AND

THEORFI ICAL PREDICIIONS 
INATPREIATON OF WAVE LENGIH DATA

The respective values of $C_{L}$ for frequencies from $5000 \mathrm{cycles} / \mathrm{sec}$ to $9000 \mathrm{cycles} / \mathrm{sec}$, Inclustve, were: $6.70 \times 10^{4} \mathrm{~cm} / \mathrm{sec}, 6.48 \times 10^{4} \mathrm{~cm} / \mathrm{sec}, 7.14 \times 10^{4} \mathrm{~cm} / \mathrm{sec}$, $6.40 \times 10^{4} \mathrm{~cm} / \mathrm{sec}, \mathrm{ylalaing}$ an average $\mathrm{C}_{2}=6.73 \times 10^{4}$ $\mathrm{cm} / \mathrm{sec}$. This value of $\mathrm{C}_{\mathrm{L}} \lambda_{\mathrm{L}}$ (Prequeney) compares with the value of $C_{L}$ obtained by computing $C_{L}=\sqrt{\frac{Y}{p}}=6.61 \times 10^{4}$ $\mathrm{cm} / \mathrm{sec}$. The two values average to $6.67 \times 10^{4} \mathrm{~cm} / \mathrm{sec}$. The computed values of $C_{T}=\lambda_{T} x$ (frequency) were: $2.1 \times 10^{4} \mathrm{~cm} / \mathrm{sec}, 2.29 \times 10^{4} \mathrm{~cm} / \mathrm{sec}, 2.32 \times 10^{4} \mathrm{~cm} / \mathrm{sec}$. $2.12 \times 10^{4} \mathrm{~cm} / \mathrm{sec}$. The average value of $\mathrm{C}_{\mathrm{r}}$ is $2.20 \times 20^{4}$ $\mathrm{cm} / \mathrm{sec}$. We were unable to compaxe this value of $\mathrm{C}_{\mathrm{T}}$ wh the value $C_{T}=\sqrt{\frac{\text { Tension in dyres }}{\text { area density tont }}}$, obtalned in terms of the elastic constants of the material. 


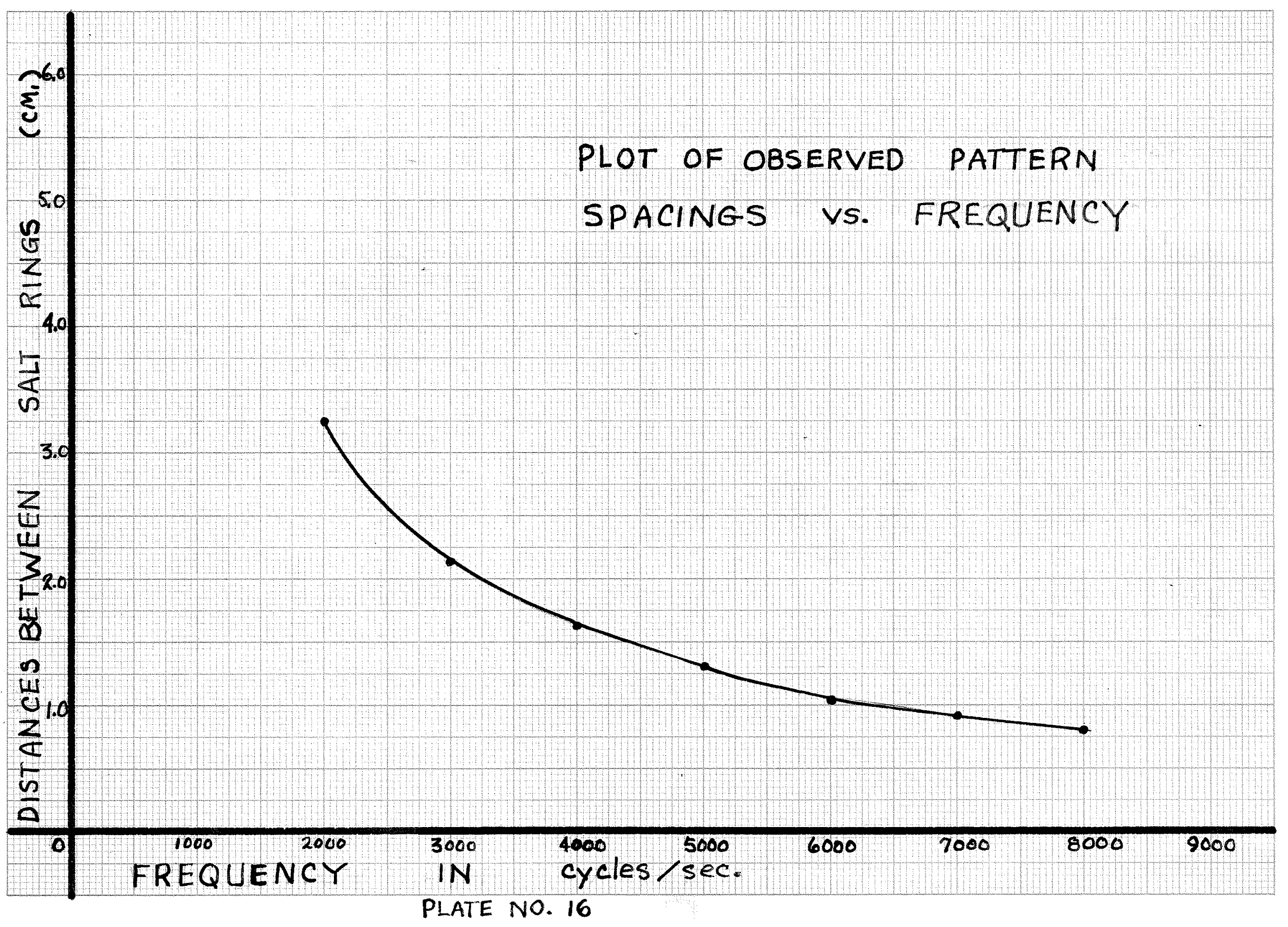


CONDOW

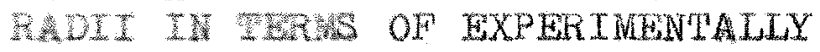
DWWERTHED WLUES OF AND

Using the relationshtp $x=\frac{P \lambda_{L} \lambda_{T}}{2\left(\lambda_{L}-\lambda_{T}\right)}$ :

$I$ (a) For $f=5 \times 10^{3}$ cycles $/ \mathrm{sec}, \frac{\lambda_{L} \lambda_{r}}{\lambda_{L}-\lambda_{T}}=6.117 \mathrm{~cm}$. $X=(.5,1.0,1.5, \ldots) 6.117 \mathrm{~cm}$. theoretical

$$
=3.058,6.117, \ldots \mathrm{cm}_{\bullet}=(2.39) \mathrm{x}_{\text {observed }}
$$

II(a) For $f=6 \times 103$ eycles/sec $\frac{\lambda_{L} \lambda_{T}}{\lambda_{L}-\lambda_{r}}=5.53 \mathrm{~cm}$.

$\mathrm{x}_{\text {theo. }}=2.765,5.53, \ldots \mathrm{cm}=(2.6) \mathrm{x}_{\mathrm{obs}}$.

$\operatorname{IrI}(\mathrm{a})$ For $f=7 \times 10^{3} \mathrm{eycles} / \mathrm{sec} \cdot \frac{\lambda_{L} \lambda_{T}}{\lambda_{L}-\lambda_{T}}=4.93 \mathrm{~cm}$. $x_{\text {theo. }}=2.47,4.93, \ldots \mathrm{cm} .=(2.71) x_{\text {obs: }}$

IV(a) For $f=8 \times 10^{3} \mathrm{cycles} / \mathrm{sec}, \frac{\lambda_{L} \lambda_{T}}{\lambda_{L}-\lambda_{T}}=3.98 \mathrm{~cm}$.

$x_{\text {theo. }}=1.99,3.98, \ldots \mathrm{cm} .=(2.48) x_{\text {obs: }}$

(Average) $x_{\text {theo. }}=(2.54) \mathrm{x}_{\text {obs: }}$ :

Using the relationship $X=\frac{P \lambda_{L} \lambda_{T}}{4\left(\lambda_{L}-\lambda_{T}\right)}$;

$I(b)$ For $t=5 \times 103$ cycles/sec.,

$$
\begin{aligned}
x & =(.25,0.5,1.0, \ldots) 6.117 \mathrm{~cm} . \\
& =1.529,3.058,4.59,6.117, \ldots \mathrm{cm} .=1.2 x_{\mathrm{obs}} .
\end{aligned}
$$

II(b) For $\mathrm{f}=6 \times 10^{3} \mathrm{cycles} / \mathrm{sec}$,

$x_{\text {theo: }}=1.382,2.765,4.14,5.53 \ldots \mathrm{cm} .=1.35 x_{\text {obs }}$

$\operatorname{III}(b)$ For $f=7 \times 10^{3} \mathrm{cycles} / \mathrm{sec}$,

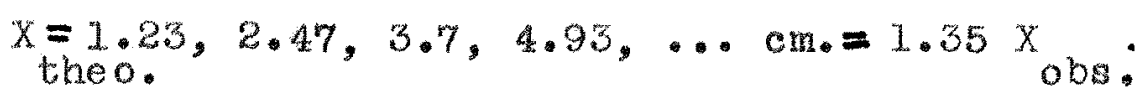

IV(b) For $f=8 \times 10^{3}$ cycles/sec.,

$x_{\text {theo. }}=1.99,2.98, \cdots \mathrm{cm}=1.243 \mathrm{x}_{\text {obs }}$ :

(Average) $x_{\text {theo }}=1.285 \mathrm{x}_{\text {obs: }}$ 
CONCLUSTON 


\section{CONOLUSION}

The form of the space equation, that we have developed to explatn the behavior of the particles, expresses the desired continulty of dependence of radial particle collection alstances upon the frequency. It was, therefore, disheartening to view the computed values for pattern spacings that averaged 2.54 and 1.285 times the observed spaelngs for veloclty and kinetic energy considew atlons, respectively. One might like to attribute the discrepancies in our results to faulty measurements, since only a decrease in the values of $\lambda$ 's would be necessary to improve the theoretical values to the desired degree of accuracy.

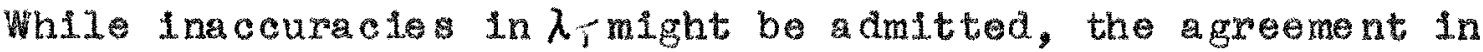
the values of $\lambda_{2}$ as determined by the two methods described in the data section serves to justify the employment of the crystal phonograph cartridge method of segregated wave detection, where two Lndependent types of wave notion co-exist simultaneously.

Ihough expressing the desired form of relationship between the vaxiables involved, the resulting spacing equetions imply to the investigator that there is definite need for refinemert of the theoretical approach.

The consideration of the kinetic energy of the membrane was not carried further because a function of the type $\left(\sin ^{2}\right.$ $\left.a x+R \sin ^{2} b x\right)$, where $R 1 s$ a function of the frequency and 


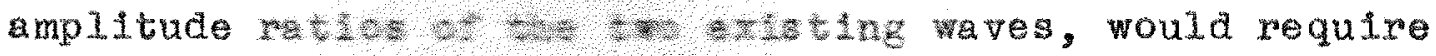

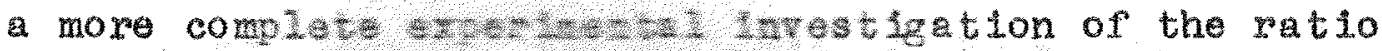

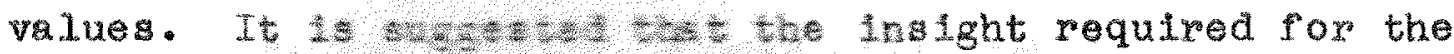

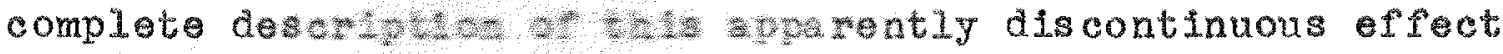

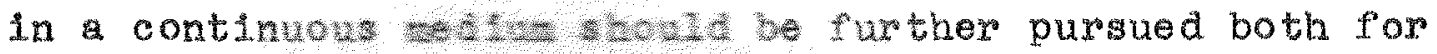

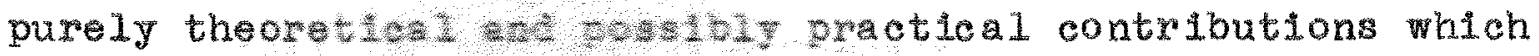
might evolve. 


\section{BIBLTOQRAPHY}

1. Slater, John $\mathrm{O}$. , and Nathaniel H. Frank, Mechanios. New York and London: McGraw-H111 Book Company, Ine., 1944.

2. Page, Leigh, Introduction to Theoretical Physios. New York: D. Van Nostrand Company, Inc., 1955.

3. Love, A. E. H., A Treatise on the Mathematical Theory of Elasticity. New York: Dover Publications, 1944.

4. Rayleigh, J.W. S., The Theory of Sound. London: Maomilian and Company, Limited, 1926.

5. Morse, Philip M., VIBRATION AND SOUND. Now York, Toronto, London: MeGraw-Hill Book Company, Inc., 1948.

6. Klnsler, Lawrence E., and Austin R. Frey, Fundamenta Is or Acoustics. Now York: John Wiley and Sons, Inc., London: Chapman and Ha11, Limited, 1950. 